\title{
EDITORIAL
}

\section{Revised food labeling in North America: the blind leading the blind?}

\author{
European Journal of Clinical Nutrition (2014) 68, 1275-1276; \\ doi:10.1038/ejcn.2014.218
}

The US Food and Drug Administration (FDA) recently proposed that the Nutrition Facts label, the way North American consumers are informed about the nutritional composition of packaged foods, be redesigned. ${ }^{1}$ There are several good things to say about the proposed new label, which is easier to read, more clearly indicates the serving size and energy content of the food and includes welcome new information about potassium. However, recent comments hardly mention these things; instead, they focus on the proposal to declare the added sugars. Kessler ${ }^{2}$ argues that merely declaring added sugars does not go far enough, whereas Sylvetsky and Dietz ${ }^{3}$ argue that declaring added sugars goes too far and may confuse consumers. We are concerned that the rationale for declaring added sugars is based on popular misconceptions rather than high-quality evidence and may do harm.

In explaining why it proposes to require the declaration of added sugars in addition to total sugars, which the label currently shows, the FDA indicates that it takes into account new data, recommendations from federal agencies and expert groups, citizen petitions and public comments. According to the FDA, 'On average, Americans get 16 percent of their total calories from added sugars.' However, this is misleading, as $16 \%$ is the estimated added sugars intake for children and adolescents but US adults consume $\sim 13 \%$ energy from added sugars. ${ }^{4}$ It is widely believed, as FDA states, that consuming added sugars can cause people to consume less nutrient-rich foods and increase the energy intake and that added sugars are 'empty calories'. However, these oversimplifications are not supported by highquality evidence.

In fact, we do not know how much added sugars Americans consume, because the US Department of Agriculture nutrient database does not contain any values for added sugars; even values for total sugars are missing for over $23 \%$ of the 8463 foods in the database. ${ }^{5}$ Thus, published information about the amount of added sugars consumed by Americans are only estimates, and there is very little information about how the level of added sugars intake affects nutrient intakes in North American populations. Surely we ought to have such information before making recommendations that are aimed at reducing the intake of added sugars.

Both the FDA ${ }^{1}$ and Kessler $^{2}$ indicate that added sugars cause overconsumption of energy. The implication is that excess energy from added sugars causes weight gain and that reducing energy from added sugars will promote weight loss. Evidence supports this view to some extent, but not entirely. A recent WHO-sponsored meta-analysis showed that reducing the intake of energy from added sugars reduces excess body fat in adults, but not in children, and no difference was seen where added sugars isocalorically replaced other sources of carbohydrate. ${ }^{6}$ In addition, the data are open to various interpretations. The CArbohydrate Ratio Management in European National diets (CARMEN) study, ${ }^{7}$ the results of which were included in the WHO meta-analysis, is the largest and longest trial to date to use an ad libitum design to assess the effect of sugars on weight gain.
It compared between an ad libitum high-sugar diet ( 55\% energy carbohydrate, $29 \%$ energy sugars) and an ad libitum highcomplex-carbohydrate diet ( 51\% energy carbohydrate, $19 \%$ energy sugars); more weight tended to be lost on the highcomplex-carbohydrate diet ( -1.8 vs $-0.9 \mathrm{~kg}$, ns). However, participants on the high-sugar diet lost significantly more weight than those on the ad libitum control (higher fat) diet ( 46\% energy carbohydrate, $21 \%$ energy sugars; -0.9 vs $+0.8 \mathrm{~kg}$, $P<0.05)$. Thus, people can lose weight on an energy-reduced diet even if it is high in simple sugars.

Both the FDA (1) and Kessler (2) suggest that it is well known that the consumption of foods containing added sugars is at the expense of nutrient-dense foods. If this were so, then people with the highest intakes of added sugars would have lower intakes of vitamins and minerals than those with the lowest intakes of added sugars. However, UK survey data (1087 men and 1110 women aged 16-64 years) show that people with intakes of added sugars in the second ( $10 \%$ energy) or third ( $13 \%$ energy) quintiles tended to have higher intakes of nutrients such as calcium, iron and folate than those in both the lowest (5\% energy) and highest $(22 \%$ energy) quintiles of added sugars intake. ${ }^{8}$ Similar observations were shown across octiles of added sugar exposure (where the lowest and highest level of exposures were $\leqslant 5 \%$ and $\geqslant 35 \%$, respectively) in the National Health and Nutrition Examination Survey in different sex and age groups for calcium, vitamin A, vitamin $E$ and iron, with few exceptions. ${ }^{9}$ Some foods containing added sugars, such as sweetened breakfast cereals, contain more nutrients than their unsweetened counterparts, and some nutritious foods such as yogurt, high-fiber breakfast cereals and canned beans are made palatable by the addition of sugars. Undue avoidance of foods containing added sugars could have the deleterious effect of reducing intakes of certain nutrients; even wholewheat bread could be avoided because it contains $2-3 \mathrm{~g}$ of sugars per slice.

The public demand for information about added sugars in foods is driven by the media, which sells its stories by providing the public with sensational news; however, stories about the toxic effect of added sugars often contain dangerously exaggerated and incorrect information. For example, a story aired on national television in Canada recently ${ }^{10}$ featured a nutritionist (rather than a qualified Registered Dietitian) who indicated that the most sugar you could have without increasing the risk of death is two sugar cubes $(8 \mathrm{~g})$ per day. She then went on to indicate the amount of sugar contained in a breakfast meal of bagel, peanut butter and jam: $4 \mathrm{~g}$ in the bagel, $8 \mathrm{~g}$ in the peanut butter and $48 \mathrm{~g}$ in $2 \mathrm{tbsp}$ of jam. Not only was the stated recommended maximum sugar intake (1.6\% energy) 3-15 times less than what is actually recommended, but also the bagel meal was said to contain nearly 3 times more sugar than it actually contains $(17 \mathrm{~g}, 4 \mathrm{~g}$ in the bagel, $3 \mathrm{~g}$ in a 2-tbsp serving of peanut butter and $10 \mathrm{~g}$ in a 1-tbsp serving of jam). No wonder the public is scared!

As physicians with an interest in nutrition, we are not going to tell people to eat more sugar. However, we believe, along with Joanne Slavin, ${ }^{11}$ that driving out added sugars could detract from public health; like the blind leading the blind, we could all fall into a pit. 


\section{CONFLICT OF INTEREST}

Thomas Wolever is a part owner, President and Medical Director of Glycemic Index Laboratories, Toronto, Canada, and has authored several popular diet books on the glycemic index, for which he has received royalties from Phillipa Sandall Publishing Services and $C A B I$ Publishers. He has received consultant fees, honoraria, travel funding, or research support from or served on the scientific advisory board for CIHR, CDA Dairy Farmers of Canada, McCain Foods, Temasek Polytechnic, Northwestern University, Royal Society of London, Glycemic Index Symbol program, CreaNutrition AG, McMaster University, Canadian Society for Nutritional Sciences, National Sport and Conditioning Association, Faculty of Public Health and Nutrition-Autonomous University of Nuevo Leon, and the Diabetes and Nutrition Study Group of the European Association for the Study of Diabetes. His wife is an employee and part owner of Glycemic Index Laboratories. Dr John L Sievenpiper has received research support from the Canadian Institutes of health Research (CIHR), Calorie Contro Council, The Coca-Cola Company (investigator initiated, unrestricted), Dr Pepper Snapple Group (investigator initiated, unrestricted), Pulse Canada, and The International Tree Nut Council Nutrition Research \& Education Foundation. He has received travel funding, speaker fees, and/or honoraria from the American Heart Association (AHA), American College of Physicians (ACP), American Society for Nutrition (ASN), National Institute of Diabetes and Digestive and Kidney Diseases (NIDDK) of the National Institutes of Health (NIH), Canadian Diabetes Association (CDA), Canadian Nutrition Society (CNS), University of South Carolina, University of Alabama at Birmingham, Oldways Preservation Trust, Nutrition Foundation of Italy (NFI), Calorie Control Council, Diabetes and Nutrition Study Group (DNSG) of the European Association for the Study of Diabetes (EASD), International Life Sciences Institute (ILSI) North America, International Life Sciences Institute (ILSI) Brazil, Abbott Laboratories, Pulse Canada, Canadian Sugar Institute, Dr Pepper Snapple Group, The Coca-Cola Company, Corn Refiners Association, and World Sugar Research Association. He has consulting arrangements with Winston \& Strawn LLP and Tate and Lyle. He is on the Clinical Practice Guidelines Expert Committee for Nutrition Therapy of both the Canadian Diabetes Association (CDA) and the European Association for the Study of Diabetes (EASD), and also is on the American Society for Nutrition (ASN) writing panel for a scientific statement on the metabolic and nutritional effects of fructose, sucrose, and high-fructose corn syrup. He is a member of the International Carbohydrate Quality Consortium (ICQC) and Board Member of the Diabetes and Nutrition Study Group (DNSG) of the EASD. He serves as an unpaid scientific advisor for the International Life Science Institute (ILSI) North America, Food, Nutrition, and Safety Program (FNSP). His wife is an employee of Unilever Canada.

TMS Wolever $^{1,2,3,4}$ and JL Sievenpiper ${ }^{1,2,3,4}$ ${ }^{1}$ Department of Nutritional Sciences, Faculty of Medicine, University of Toronto, Toronto, Ontario, Canada;

${ }^{2}$ Toronto 3D (Diet, Digestive Tract and Disease) Knowledge Synthesis and Clinical Trials Unit of the Clinical Nutrition and Risk Factor Modification Centre, St Michael's Hospital, Toronto, Ontario, Canada;

\author{
${ }^{3}$ Division of Endocrinology and Metabolism, St Michael's Hospital, \\ Toronto, Ontario, Canada and \\ ${ }^{4}$ Keenan Research Centre of the Li Ka Shing Knowledge Institute, \\ St Michael's Hospital, Toronto, Ontario, Canada \\ E-mail: thomas.wolever@utoronto.ca
}

\section{REFERENCES}

1 Proposed Changes to the Nutrition Facts Label. Food and Drug Administration: Silver Spring, MD, USA. http://www.fda.gov/Food/GuidanceRegulation/Guidance Documents_RegulatoryInformation/LabelingNutrition/ucm385663.htm. Accessed 21 July 2014.

2 Kessler DA. Toward more comprehensive food labeling. N Engl J Med 2014; 371: 193-195.

3 Sylvestsky AC, Dietz WH. Nutrient-content claims - guidance of cause for confusion? N Engl J Med 2014; 371: 195-198.

4 Ervin RB, Ogden CL. Consumption of Added Sugars Among U.S. Adults, 2005-2010. NCHS Data Brief No. 122. 2013, National Center for Health Statistics: Hyattsville, MD, USA.

5 Composition of Foods Raw, Processed, Prepared USDA National Nutrient Database for Standard Reference, Release 26: Documentation and User Guide. November 2013, US Department of Agriculture: Beltsville, MD, USA. http://www. ars.usda.gov/sp2UserFiles/Place/12354500/Data/SR26/sr26_doc.pdf. Accessed 21 July 2014.

6 Te Morenga L, Mallard S, Mann J. Dietary sugars and body weight: systematic review and meta-analyses of randomised controlled trials and cohort studies. BMJ 2013; 346: e7492.

7 Saris WHM, Astrup A, Prentice AM, Zunft HJF, Formiguera $X$, Verboeket-van de Venne WPHG et al. Randomized controlled trial of changes in dietary carbohydrate/fat ratio and simple vs complex carbohydrates on body weight and blood lipids: the CARMEN study. Int J Obesity 2000; 24: 1310-1318.

8 Gibson SA. Do diets high in sugars compromise micronutrient intakes? Micronutrient intakes in the Dietary and Nutritional Survey of British Adults according to dietary concentration of 'added', 'non-milk extrinsic' or 'total' sugars. J Hum Nutr Dietet 1997; 10: 125-133.

9 Food and Nutrition Board, Institute of Medicine. Dietary Reference Intakes for Energy, Carbohydrate, Fiber, Fat, Fatty Acids, Cholesterol, Protein, and Amino Acids (Macronutrients). The National Academies Press: Washington, DC, USA, 2005

10 Top hidden sugar foods. Theresa Albert on Stephen and Chris, Season 7, Episode 10. http://www.cbc.ca/player/Shows/Shows/Steven+and+Chris/Segments/ ID/2475975762/. Accessed 23 July 2014.

11 Slavin J. Two more pieces to the 1000-piece carbohydrate puzzle. Am J Clin Nutr 2014; 100: 4-5. 